\title{
Germanica
}

\section{Document inédit Plan pour un numéro cinéma de Micromégas}

\section{Siegfried Kracauer}

\section{(2) OpenEdition}

\section{Journals}

Édition électronique

URL : https://journals.openedition.org/germanica/9196

DOI : 10.4000/germanica.9196

ISSN : 2107-0784

Éditeur

Université de Lille

Édition imprimée

Date de publication : 1 juin 2020

Pagination : 183-184

ISBN : 978-2-913857-45-2

ISSN : 0984-2632

Référence électronique

Siegfried Kracauer, «Document inédit Plan pour un numéro cinéma de Micromégas », Germanica [En

ligne], 66 | 2ème trimestre 2020, mis en ligne le 02 janvier 2022, consulté le 08 janvier 2022. URL http://journals.openedition.org/germanica/9196 ; DOI : https://doi.org/10.4000/germanica.9196

(c) Tous droits réservés 


\section{Document inédit Plan pour un numéro cinéma de Micromégas}

Siegfried Kracauer

Dans le cadre de la parution prochaine des Écrits français de Siegfried Kracauer, les éditeurs nous ont permis de reproduire un des documents inclus dans leur publication.

Siegfried Kracauer, ÉCRITS FRANÇAIS. Articles et critiques, inédits, correspondance 1933-1941

Stephanie Baumann et Nia Perivolaropoulou (éd.),

Montréal, Presses de l'Université de Montréal / Paris, Éditions de la MSH, 2020

Les écrits réunis dans ce volume appartiennent à la période de l'exil de S. Kracauer en France entre 1933 et 1941. Tantôt des traductions (auxquelles il a parfois pu collaborer), tantôt des documents rédigés directement en français, ces textes dressent une image précise de son activité multiforme d'analyste, de critique et d'écrivain, ainsi que de ses nombreuses relations avec des intellectuels français pendant cette sombre période. Un choix de lettres de Kracauer accompagne la publication de ces articles parus anonymement sur la situation en Allemagne, critiques et textes inédits.

Le document ci-après « Plan pour un numéro cinéma de 'Micromégas' » fait partie de la section des textes et projets inédits. Ce plan conçu en 1938 s'inscrit dans le sillage de l'activité de critique de films de Kracauer, mais les circonstances dans lesquelles il a développé sa proposition restent toutefois inconnues. Le sommaire qu'il propose renvoie aussi bien à des 
articles contemporains qu'il a pu publier, en français ou en allemand dans les journaux suisses, qu'à des sujets dont il s'est toujours préoccupé : l'histoire du cinéma, le burlesque ou des réalisateurs dont il avait souvent commenté les films. Deux nouveaux thèmes apparaissent cependant : la fonction de la représentation filmique de la terreur et la propagande cinématographique, qu'il ne cessera désormais d'explorer.

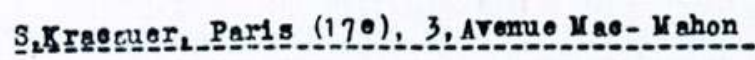

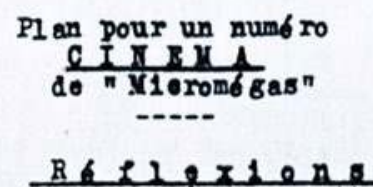

1) Quelques aperpus pourant servir dintroduotion ane H1stolre Im th olnena. (Jo mo ohargeral s ro1 metno de oet artiole.)

2) Io film comme instrument de la propagande.

3) Le rôlo des solnes de terreur et de panique dans $10 \mathrm{ellm}$.

4) Ies fonetions soolales du oinéma permanent.

$$
\text { cenerentations at } x<1010 n=
$$

Dans eette partio on derralt falre efat des surprises sourent sonsationnelles qu'on éprouve en revojent de vieux flis. Jo propose:

1) Un artiol sur 10 oinéma súdois,

2) Un art1 ol our le oinéma russo. ( Ios Mlms de Poudovkine par exemplo ont torriblenont vio1111. J'almeral à érir Justement id-descus.)

\section{sil 1 h o t t 5}

J'y penso h des apergus tres serrós sur quelques personnages et évelnements du muet frangals. Volla ma proposition:

1) Ranil tohl (b l'o ceasion d'un do ses dessins animés)

2) Fruill ade ( $n$ Tantomasn)

3) Max Inder (" Ro1 an Cirque")

4) Lous Delluo ("Fato espegnoln)

5) Yaroel I'Horbier (" Pur Hath1 as Pasoal")

6) I. Caval oant1 (" Bn rade")

7) René C1alr ("I es derx tim1des")

8) Jean Vigo ("

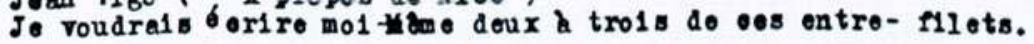

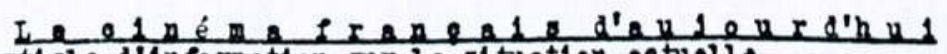

1) Un artiolo d'information sur la situation actuolio

2) Fos quall tés ot los dangers du fll franpas - artiolo dont j'almerale Fo oharger, on donnant uns onalyso do hal dos Brumesn

3) I'Influenee du olnéma frangal a i'stranger ot surtout en mérique.

4) Une enquête sur ies projeto de í produotion irangaleo.

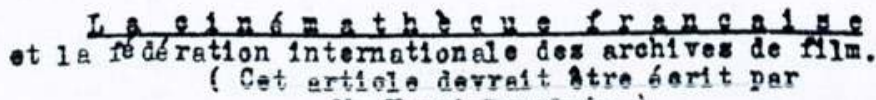

$$
\begin{aligned}
& \text { i. Eenri Langlois.) }
\end{aligned}
$$

Siegfried Kracauer : Plan pour un numéro cinéma de Micromégas, 15.09.1938. Fonds Kracauer [72.3627], Deutsches Literaturarchiv Marbach. 